\title{
ProSeBiCA:
}

\section{Development of new library services by means of Conjoint Analysis}

\author{
Antonia Hermelbracht \\ Department of Business Administration and Economics, University of Bielefeld, \\ Bielefeld, Germany \\ Bettina Koeper \\ Bielefeld University Library, Bielefeld, Germany
}

\begin{abstract}
Purpose: Description of the project ProSeBiCA, carried out in order to adapt the marketing research tool Conjoint Analysis for the development of future library services. The paper describes the methodical approach, and provides an overview of the results gained by several user surveys.
\end{abstract}

Design/methodology/approach: The methodical approach includes the use of Adaptive Conjoint Analysis (ACA) and Choice-Based Conjoint Analysis (CBC).

Findings: Conjoint Analysis is an appropriate tool for the strategic development of library services. It provides detailed results by identifying users' preferences towards concrete services, and allows to deduce general statements about future trends for library services.

Research limitations/implications: Future plans include cooperation with the Sheridan Libraries at Johns Hopkins University (Baltimore, Maryland), the Association of Research Libraries (ARL), and other interested partners in order to adapt the ProSeBiCA framework for U.S. libraries and to integrate techniques used by the partners (CAPM, LibQUAL $+{ }^{\mathrm{TM}}$ ). The extension of Conjoint Analysis to the evaluation of services for a fee will be an additional area of research.

Practical implications: Service orientation in libraries can be based on a systematic approach. Depending on local circumstances, interested libraries can improve their service orientation in different ways, either by discussing the results of the analysis made in this project or by using the Conjoint Analysis questionnaire for a survey in their institutions.

Originality/value: The paper describes the current status and provides the latest results of ProSeBiCA. It is of interest to library managers and marketing researchers.

Keywords: Information services, Market research, Surveys, Academic libraries, Germany

Paper type: Research paper

In the context of changing educational environments, current discussions about the strategic development of German academic libraries clearly show the need for a basic change in the way they see themselves. They need to evolve from mere academic institutions into service providers which actively design and offer services that fit users' needs and preferences. More and more customer take-up of library services is becoming a new quality standard that will have a significant effect on the status of libraries within universities, particularly in times of small budgets and growing autonomy in academia. In order to achieve this take-up, libraries need to establish and improve their customer relations, and above all they have to develop a profound knowledge of their users and their needs. But how can we get this knowledge in a systematic way? How can we get a clear idea of user preferences in order to shape future library services?

The project ProSeBiCA, funded by the German Research Foundation (DFG) and carried out jointly by the Chair of Marketing at Bielefeld University and 
Bielefeld University Library, tries to answer these questions. The name "ProSeBiCA" is an acronym of the German project title that can be translated as "Prospective control of the services of academic libraries by means of Conjoint Analysis". It suggests the idea behind the project, which is to adapt Conjoint Analysis to create an appropriate tool for library managers. Now, what exactly is meant by Conjoint Analysis?

\section{Conjoint Analysis: a short definition}

Conjoint Analysis is a well established marketing research method which aims to examine customer preferences empirically. It also aims to simulate the users' potential decisions on the use of products or services. In other words: Conjoint Analysis offers a mechanism for measuring user take-up, in particular, take-up of new products and services which have yet to be developed. Conjoint Analysis does not formulate the problem in terms such as: "How does a customer value a certain service in its current form?", but "What service or what level of service will yield the greatest value to the customer?" and, in a second step, "Which of these options should be incorporated into the future range of services?" Hence Conjoint Analysis is a proactive method that aims to give a picture of the future shape of services. It is widely used in commercial applications, mostly in the fields of pricing policy and development of new products. In contrast, it is not common in the public sector, with the exception of public health services.

First of all, there are a few technical terms connected with Conjoint Analysis which should be introduced. Conjoint Analysis always distinguishes between "attributes" and "levels". Products or services (e.g. library news bulletins) are "attributes", and their potential forms (e.g. library news bulletins provided in print form on flyers, or in electronic form via e-mail) represent the "levels". Customers have to choose between these possible levels, thus expressing their preferences. Combining levels of different attributes allows service offerings to be defined. They can then be compared according to their value to customers. However, Conjoint Analysis is not only able to reveal the preferences of the customer-base as a single entity. It also allows group specific analysis. The "a-priori segmentation" looks at the preferences of respondents who have been divided into segments defined by demographic criteria (e.g. status, such as student, academic staff or administrative staff). By interpreting the results of a Conjoint Analysis survey it is also possible to group the respondents according to the "part-worth utilities" (output of the Conjoint Analysis representing the particular values of the single attribute levels) they ascribe to a product, this is the so-called "benefit segmentation".

\section{Aims and procedures of the ProSeBiCA project}

The aim of the ProSeBiCA project is to adapt Conjoint Analysis as a tool for the strategic development of academic libraries. This means the developing of an analysis and simulation framework that covers the whole range of library services. This aim is twofold. Firstly, a framework has to be developed for Bielefeld University, because a methodical adaptation such as is intended by this project clearly needs a test environment. Secondly, ProSeBiCA will provide a general analysis framework and some guidelines for the application of Conjoint Analysis in other academic libraries. In this spirit, the project is to give an insight into what 
users may expect from their library and to identify future trends that are relevant for the development of library services.

A project like this one, with the intention of adapting a complex marketing research method for library services, clearly depends on a practical background as well as on academic management input. In this way it forms a perfect basis for the cooperation of a university library and faculty. Hence, ProSeBiCA is a cooperative project carried out jointly by Bielefeld University Library and the Chair of Marketing at the local Department of Economics and Business Administration. The project passed several milestones, the first one being to generate ideas. This step was preparation for the Adaptive Conjoint Analysis survey (ACA) at Bielefeld University in Autumn 2004 as well as for the Choice-Based Conjoint Analysis survey (CBC) in Bielefeld from May to June 2005. The next milestone, the combined ACA and CBC survey at Brandenburg Technical University Cottbus, ran from November 2005 to January 2006. The latter survey covered the same questions as the previous two studies in Bielefeld, and the evaluation and interpretation of the results is currently (as of February 2006) still ongoing. This milestone, requiring cooperation with the Information, Communication and Media Center (IKMZ), as well as with the Chair of Marketing and Innovation Management at Cottbus University, is of great importance, as it is to ensure the transferability of the approach developed at Bielefeld. This finally leads on to the last milestone, which includes general statements and results, as well as the general framework and the guidelines already mentioned.

Alongside ProSeBiCA, there was an information exchange with the Sheridan Libraries at Johns Hopkins University, who applied a similar methodical approach in their project Comprehensive Access to Printed Materials (CAPM). Previous considerations about possible connections between CAPM and LibQUAL $+{ }^{\mathrm{TM}}$, a methodology developed by the Association of Research Libraries (ARL) and Texas A\&M University Libraries (Choudhury et al., 2002; Heath et al., 2003), also led to further contacts with $A R L$ and other interested partners. As a result of these contacts a working plan was established to adapt the ProSeBiCA framework for U.S. libraries. Taking a step forward, a plan was also established to integrate the techniques offered by these three methodical approaches (CAPM LibQUAL+ ${ }^{\mathrm{TM}}$ - ProSeBiCA) with the aim of developing a homogenous tool and portal as a support system for library management decision-making processes.

\section{Empirical studies at the Universities of Bielefeld and Cottbus}

Idea generation step

In order to cover all relevant, possible and desirable future library services, a variety of activities were started during Spring 2004. Firstly, a comprehensive content analysis of secondary data sources was carried out. These included, in particular, articles in library journals, political papers as well as websites of a broad range of libraries all over the world. Subsequently, the ideas and opinions of 1,349 academic library users at four different German universities concerning the services offered by academic libraries were collected by means of an empirical survey. In addition, new service ideas were generated by academics and librarians in a total of five structured brainstorming workshops. Furthermore, library usage data from Bielefeld University Library was analyzed by means of an artificial neural network approach in order to identify usage patterns that support the qualitative new service creation process (cf. Decker and Hermelbracht, 2005). Altogether it 
was possible to identify some controversial strategic themes and - from an operative perspective - more than 250 concrete new ideas for services.

From the strategic perspective, it was possible to identify areas such as the degree of digitization at the library, the level of support for users by librarians, or the amount of services available for a fee. The six most relevant areas were integrated in two Choice-Based Conjoint Analysis surveys (CBC) at Bielefeld University and Cottbus University. This selection was also based on the results of the operative perspective (see below).

From the operative perspective, there was an abundance of ideas about many different areas. A detailed list of these concrete ideas for new services is given in Hermelbracht and Senst (2005). A database with an up-to-date pool of ideas is available from the ProSeBiCA-project homepage [1]. Two short examples serve to illustrate the spectrum of ideas. An example of a more technical service could be a video-mediated book-view, where users can read and scroll through a book online via a high-resolution video. Another innovation especially for new users could be the starter pack, including a virtual short introduction to using the library for freshers as well as a glossary for foreign students with translations of important library terms into several languages. In the end, the challenge of structuring and handling this variety of ideas appropriately was met by allocating the service ideas to the following areas: provision of media, learning and working environment, communication, and additional services. These areas are part of an integrated structure, into which any current or potential service of a university library can be clearly slotted. Provision of media, the learning and working environment and communication are part of the core business of a university library. Each of the four areas was evaluated separately by an Adaptive Conjoint Analysis (ACA) that first took place in an empirical survey at Bielefeld University and then in a second one at Cottbus University.

\section{Questionnaire}

For the two surveys in Bielefeld (ACA and CBC), as well as the survey in Cottbus, we used the two worldwide most popular online conjoint software packages offered by Sawtooth Software. In applying the ACA it was possible to use its advantages, such as its handling of a large number of attributes and levels, dynamic question creation, and calibration of utilities for market simulations. The Adaptive Conjoint Analysis contains compositional as well as decompositional parts and gathers the different parts of information using four kinds of questions. The Choice-Based Conjoint Analysis takes the choice-behavior of the consumers into account, and reflects new research developments in the area of Conjoint Analysis. CBC is more appropriate for scenarios with fewer attributes, as in the case of strategic perspectives. The respondent can compare different complete profiles and choose one of them. A description of these conjoint techniques in the context of the current project is given in Decker and Hermelbracht (2006). A visualization of the ACA questions can be seen in Hermelbracht and Senst (2006). Due to the very large amount of ACA attributes (42) and levels (118), they cannot be presented here. For more information, please refer to the homepage of the project.

The CBC questionnaire used one main type of question to discover the preferences of library users (see Figure 1). This study considered six attributes with two or three levels. The attributes were: 
- innovation strategy,

- level of support,

- degree of digitization,

- degree of specialization,

- $\quad$ add-on services with costs, and

- $\quad$ presentation of services.

The three levels of the innovation strategy were reactive (demand-oriented innovations), selective (innovation in selected areas), and progressive (strict innovation-orientation). The level of support can vary from unsupported / independent working, via assisted working, to delegating tasks to librarians. In order to evaluate the preferred degree of digitization, the scenario of a conventional library with digital services was differentiated from that of a

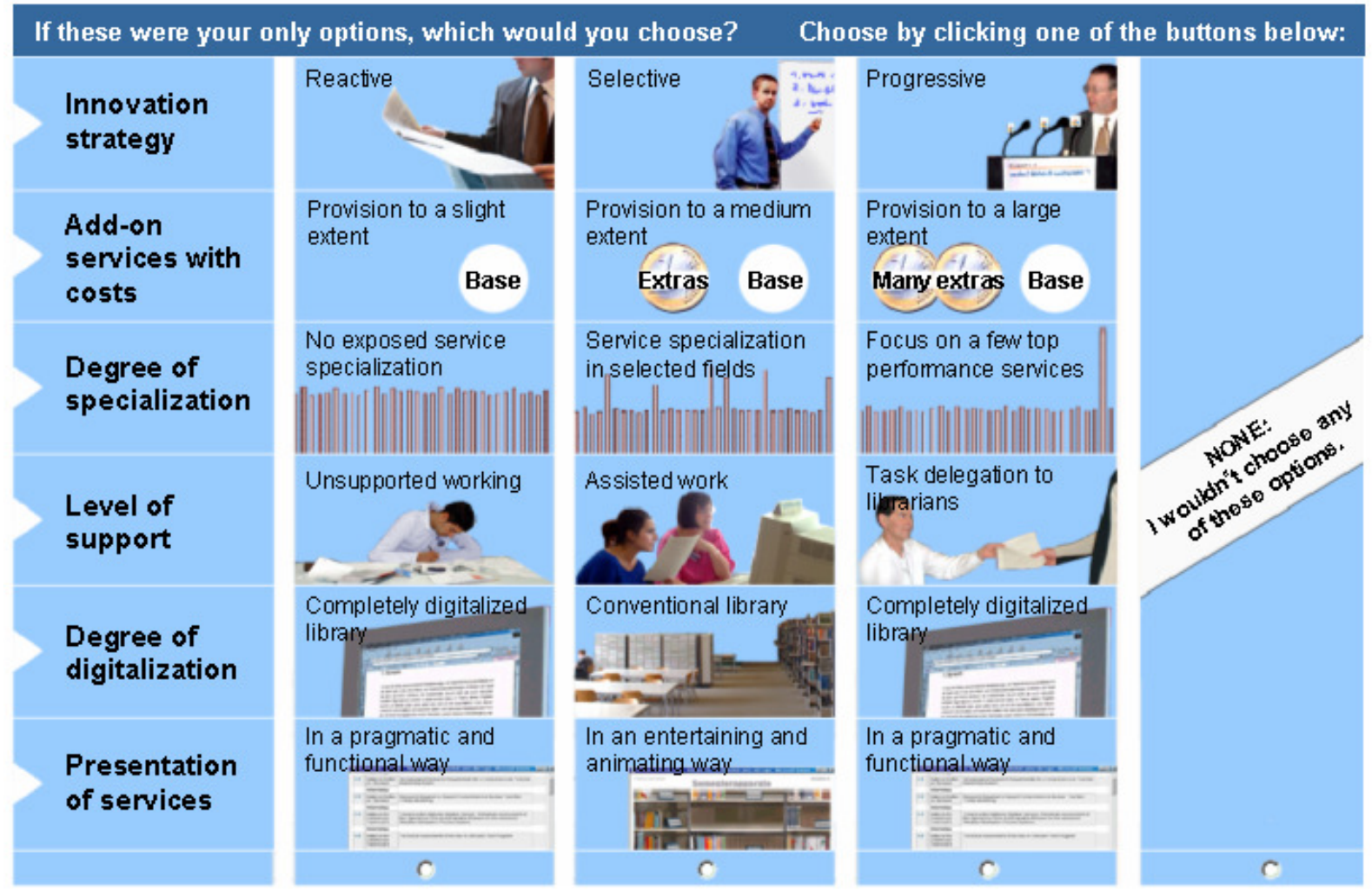

Figure 1: Sample CBC choice task

completely digitized library existing only in cyberspace. The level of specialization of regularly offered services which should be striven for in the future, can be decided from the following three options: no emphasized service specialization, service specialization in selected fields, or a focus on a few top performance services. The fifth attribute considers the role of chargeable secondary services, which can be provided to a small, medium or large extent. Lastly, the services can be presented in two opposing ways: either in a pragmatic and functional way, or in an entertaining and animating way. Which of these options were preferred in both surveys will be analyzed next in a short presentation of the survey results. 


\section{Implementation and general results}

The first ACA survey at Bielefeld University (October to December 2004) collected 2,120 answers over an eight week period. The second CBC survey at Bielefeld University took place from May to June 2005 and gathered 1,672 responses. Lastly, the integrated ACA and CBC survey at the University of Cottbus (November 2005 to January 2006) collected the opinions of 1,127 persons. Table 1 shows the distribution of respondents according to the five different questionnaire parts. Almost 5,000 responses were gathered during the three empirical surveys.

\begin{tabular}{|l|l|l|l|l|}
\hline & ACA Bielefeld & CBC Bielefeld & $\begin{array}{l}\text { ACA/CBC } \\
\text { Cottbus } \\
03.11 .05 \\
04.01 .06\end{array}$ & - \\
& $\begin{array}{l}13.10 .04 \\
09.12 .04\end{array}$ & $-\begin{array}{l}04.05 .05 \\
30.06 .05\end{array}$ & Total: \\
\hline ACA: Provision of media & 578 & 0 & 196 & $\mathbf{7 7 4}$ \\
\hline ACA: Learning Environment & 540 & 0 & 201 & $\mathbf{7 4 1}$ \\
\hline ACA: Communication & 455 & 0 & 196 & $\mathbf{6 5 1}$ \\
\hline ACA: Additional services & 547 & 0 & 184 & $\mathbf{7 3 1}$ \\
\hline CBC: Strategic development & 0 & 1672 & 350 & $\mathbf{2 0 2 2}$ \\
\hline Total: & $\mathbf{2 1 2 0}$ & $\mathbf{1 6 7 2}$ & $\mathbf{1 1 2 7}$ & $\mathbf{4 9 1 9}$ \\
\hline
\end{tabular}

Table 1: Distribution of the responses to the three empirical surveys

In order to obtain such large samples the questionnaire was placed on each library's homepage (cf. Hermelbracht and Senst, 2006). Additionally some students helped to motivate visitors to the library and students on campus to take part in the survey, and also made phone calls to academics and to administrative staff explaining the purpose of the questionnaire. In addition, extrinsic motivation was increased by offering attractive prizes (e.g. iPod, gym memberships, theatre tickets, music CDs), which could be won by completing the questionnaire. All surveys covered the different demographic groups very well. The different user groups were represented as follows:

- in the ACA survey in Bielefeld, there were 1,685 students (equaling approximately $9 \%$ of the undergraduates, graduates, and postgraduates matriculated at Bielefeld University), 174 academic staff (equaling approximately $22 \%$ of the professors and academic assistants), and 261 others (e.g. external users);

- $\quad$ in the CBC survey in Bielefeld, there were 1,329 students, 118 academics and 225 others; and

- $\quad$ in the integrated ACA/CBC survey in Cottbus, there were 843 students, 141 academics, as well as 143 others.

More details about the demographics can be found in the project documentation [1].

ACA results

Different aspects were investigated through the analysis of the ACA data. The most important ones considered the analysis of preferences on an aggregate 
level, on an a-priori user-groups level, and on an a-posteriori benefit-segments level. In the aggregate level of analysis it was discovered that many current services (such as the conventional library catalogue search, self-administration of the loan account and the online post box) are evaluated favorably, (for more details see Hermelbracht and Koeper, 2006). Also many improvements to current services are regarded as providing a high utility (for example, an increase in printed media stock or an improved guidance system). Finally, there is a demand for many innovative ideas, such as an open-air area or starter packs. On the other hand, there are conventional features that are less desirable, such as conventional interior design and a lack of online-publishing possibilities. There is also little demand for some new service ideas, such as a radio-archive or drive-thru book lending. It can be concluded that there are differences between the evaluation of current services and new innovative ideas on the aggregate level. Altogether it was possible to identify acceptable as well as controversial innovations and provide recommendations for the future development of Bielefeld and Cottbus University Libraries. A more detailed analysis also revealed similar discrepancies in the preferences of different user groups.

The a-priori segments (such as academics, students, and others) have some preferences in common. Clear preference structures could be identified in the same way as with the aggregate analysis. Academics are more skeptical towards more "extravagant" innovations than the students and others. They also make the strongest differentiation between the different attribute levels.

Based on the part-worth utilities of the respondents a cluster analysis was carried out. As a result it was possible to identify some benefit-segments. These vary between the different service areas as well as between the Universities of Bielefeld and Cottbus. But some response patterns were seen to recur in the different sub areas. Segments with highly-involved users oriented towards innovation are typical for almost every consideration. Also, some traditional users who prefer many current services are represented in each sub area. In some of the areas, it was possible to identify groups of determined users, who differentiate very strongly between the single items, and less-interested users, who are unlikely to make great use of the services.

Comparison of the part-worth-utilities in Bielefeld and Cottbus reveals some interesting correspondences. The operative evaluations can be separated into two parts. Half of the results in Bielefeld and Cottbus are similar, and the other half contradict each other. Therefore it will be difficult to deduce general recommendations on concrete services for all libraries in Germany. Moreover, each library has its own specific situation, which should be investigated separately. It is interesting that the results become more similar if universal services such as different communication activities are considered. Then again, if more specific services such as from the learning and working environment area are considered, the differences increase.

\section{CBC results}

This impression can be confirmed by the results of the strategic CBC surveys. Here the results in both cities are very similar. The middle attribute levels are always considered as offering the highest utility, with the consequence that, for example, the users decided in favor of selective innovation strategy, assisted working (but no task delegation to librarians), and also specialization in selected 
areas. Here it is very important to stress the significance the users attribute to the conventional library as working environment with some digital media stock and services. This corresponds to the results of the ACA survey. The following outcomes also confirm the first survey results. The respondents prefer the pragmatic and functional to the entertaining and stimulating presentation of services - digital as well as those physically on site. This corresponds to the valuation of some "extras" included in the ACA survey. Finally it can be concluded that the respondents are willing to pay for some additional services, as long as these do not take precedence. A detailed consideration of the a-priori and benefitsegments, as well as extensive presentations of the ACA and CBC results, are contained in the documentation of the project and are available via the project homepage.

\section{Conclusions}

What can be said about the general outcomes of the ProSeBiCA project? It considers a very interesting and up-to-date theme. It was possible to collect very large samples and many respondents communicated their interest in this topic.

In all surveys it was possible to identify the high importance of the hybrid library, as well as of many on-site services. Altogether the significance of the core business, and especially of the provision of media, is very high. As to concrete innovations, we can clearly differentiate between those for which there is a strong demand, and others that obviously do not add any useful functionality. There is a willingness to accept new service ideas, and there are strong preferences, especially for services which facilitate immediate and effortless access to information. Alongside the benefit-segments, it was possible to identify some interesting differences between the a-priori segments, considering extras and facilities for the users.

Altogether, it can be concluded that abstract results are comparable and probably valid for other university libraries in Germany. The evaluation of concrete services depends strongly on the particular situation of the library under consideration. Libraries interested in marketing research can profit from the results of this project as a basis for future planning and are well advised to deepen their knowledge about their own users through further custom-designed surveys.

\section{Notes}

1. www.prosebica.de

\section{References}

Choudhury, S., Hobbs, B. and Lorie, M. (2002), "A framework for evaluating digital library services", D-Lib Magazine, Vol. 8, No. 7/8, available at: www.dlib.org/dlib/july02/choudhury/07choudhury.html (accessed 9 March 2006).

Decker, R. and Hermelbracht, A. (2005), "Pattern detection with growing neural networks - an application to marketing and library data", in Fleuren, $\mathrm{H}_{\text {., }}$ den 
Hertog, D. and Kort, P. (Eds.), Operations Research Proceedings 2004, Springer, Berlin, pp. 230 - 237.

Decker, R. and Hermelbracht, A. (2006), "Planning and evaluation of new academic library services by means of web-based Conjoint Analysis", forthcoming in The Journal of Academic Librarianship, November 2006.

Heath, F., Kyrillidou, M., Webster, D., Choudhury, S., Hobbs, B., Lorie, M., and Flores, N. (2003), "Emerging tools for evaluating digital library services: conceptual adaptations of LibQUAL+ and CAPM", Journal of Digital Information, Vol. 4, No. 2, Article No. 170, 2003-06-09, available at: http://jodi.tamu.edu/Articles/v04/i02/Heath/ (accessed 9 March 2006).

Hermelbracht, A. and Senst, E. (2005), "Ideen für innovative Serviceangebote von Universitätsbibliotheken - Ergebnisse der Ideengenerierungsphase im Rahmen des ProSeBiCA-Projektes an der Universität Bielefeld“", Bibliotheksdienst, Vol. 39, No. 1, pp. 50 - 75, available at: www.zlb.de/aktivitaeten/bd_neu/heftinhalte2005/betriebsorg0105.pdf (accessed 9 March 2006).

Hermelbracht, A. and Koeper, B. (2006), "Der Einsatz der Conjoint-Analyse in wissenschaftlichen Bibliotheken - Imagegewinn durch Dienstleistungsentwicklung „nahe am Kunden“, in Lülfing, D. and Siebert, I. (Eds.), 94. Deutscher Bibliothekartag in Düsseldorf 2005, Klostermann, Frankfurt am Main, pp. 78 - 92.

Hermelbracht, A. and Senst, E. (2006), "The ProSeBiCA-project: application of the Conjoint Analysis as a marketing research tool for the development and control of future academic library services", in Gupta, D. K., Koontz, C. A., Massisimo, A. and Savard, R. (Eds.), Marketing Library and Information Services: International Perspectives, K.G. Saur, Munich, pp. 300-312. 